\title{
O tempo redesenhado: tramas da imagem
}

RODRIGO FREITAS

Rodrigo Freitas graduado em Artes pela Universidade Federal de Minas Gerais com habilitação em pintura (2006) e em gravura (2008). Possui mestrado e doutorado em Artes pela mesma instituição (2016). Atualmente é professor do Instituto de Artes da Universidade Federal de Uberlândia, participa do NUPPE (Núcleo de Pesquisa em Pintura e Ensino) e pesquisa a relação entre imagem e tempo a partir da prática pictórica em diálogo com diversos meios de criação e difusão da imagem.

ouvirouver Uberlândia v. 14 n. 2 p. 322-328 jul.| dez. 2018 


\section{- RESUMO}

Esse texto investiga as relações entre imagem e tempo a partir de alguns trabalhos da artista inglesa Tacita Dean, nos quais o desenho se vê atravessado por temporalidades outras, resultantes do diálogo como a fotografia, o cinema, e a própria pintura. Pensar a imagem em trânsito por diferentes meios é uma maneira de desestabilizar a percepção linear do tempo, pois nesses deslocamentos ela se apresenta como uma constelação de tempos heterogêneos. Para além do diálogo que as obras possam estabelecer com outros campos do conhecimento (cinema, fotografia, pintura), a própria imagem, por mais antiga que seja, sempre reconfigura o presente no qual se apresenta. Diante dela somos confrontados com uma memória que nos antecede e com uma possibilidade de futuro que também nos ultrapassa. Na tremulante presença da imagem, o que se apresenta é o nosso próprio desaparecimento. Esta é a sua abertura dilacerante, que inevitavelmente nos coloca também diante do tempo.

\section{PALAVRAS-CHAVE}

Tacita Dean, imagem, tempo.

\section{ABSTRACT}

This article investigates the relations between image and time, taking as object of study some works of the English artist Tacita Dean. In her works the drawing is crossed by other temporalities, resulting from the possible dialogue with photography, cinema, and also painting. Thus, we can understand that the moving image by different media destabilizes the linear perception of time. In these displacements the image presents itself as a constellation of heterogeneous times. Besides the dialogue that these works can establish with other fields of knowledge (cinema, photography, painting), image, however ancient, always reconfigures the present in which it presents itself. As spectators we are confronted with a memory that precedes us and with a possibility of future that surpasses us. In the flickering presence of the image, what appears is our own disappearance. This is the image's lacerating opening, which inevitably also places us before the time.

\section{KEYWORDS}

Tacita Dean, image, time.

Parecia ser o mar e era o mar que fluía na superfície negra daqueles grandes quadros. Sete ao todo, dispostos lado a lado pelas paredes de uma ampla sala, como se fossem as páginas abertas de alguma epopeia ou talvez fragmentos de uma sequência cinematográfica. Um olhar mais atento, porém, revelava que aquelas imagens não criavam nenhuma narrativa, pelo menos não no sentido linear, como de início se poderia supor. Havia, entre aqueles desenhos, algo desconcertante, 
inapreensível como o próprio mar. Apesar da escala monumental daqueles quadros negros, que transbordavam as proporções humanas, reverberavam nos traços feitos de giz uma fragilidade aterradora, assinalando a impermanência de tudo. A imagem treme ou trememos diante dela? Cabe então perguntar: $\mathrm{O}$ que se esconde sob as ondas desse outro mar, desenhado no fluxo de gestos que marcam o suporte, mas que também apagam e borram os limites da imagem? Qual é o tempo que faz fluir as superfícies encrespadas das águas feitas de giz? Em que tempo se encontra a imagem diante de nossos olhos? Estaria no pretérito da lembrança ou no presente em suspensão da narrativa? São essas as perguntas que nos atingem como flechas, quando nos colocamos diante do oceano que é a imagem.
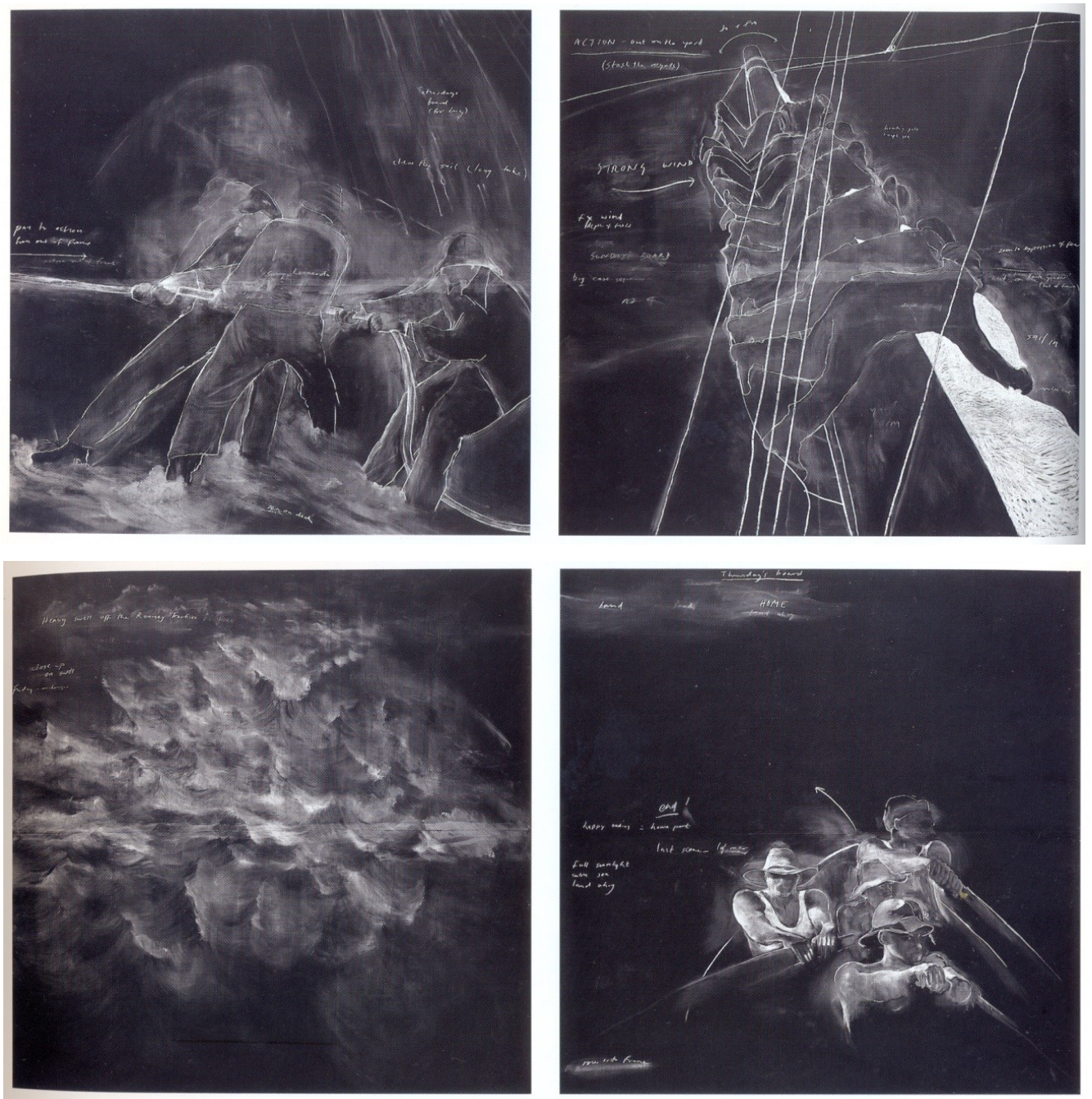

Figuras 1 e 2 - Tacita Dean. Roaring Forties II, IV, VI e VII. Giz sobre quadro negro, 240 x 240 cm, 1997. (Roaring Forties: Seven Boards in Seven Days). Coleção Tate, Londres. Fonte: ROYOUX, Jean-Christophe. Tacita Dean. Londres/ Nova York: Phaidon, 2006, p. 26. 
Nesses quadros da artista inglesa Tacita Dean, o desenho se faz em ato, repetindo os fluxos e refluxos dos mares, cujas ondas, durante a noite, espraiam inquietas pelas areias brancas e depois arrastam tudo o que encontram para as profundezas sem rosto. Ficam as marcas da espuma espessa, como os apagamentos do desenho. Assim também nos perdemos nesse mar desdobrado sobre o quadro negro, como a própria superfície do oceano. Vemos então, como se um facho de luz iluminasse na noite escura as águas agitadas pela tempestade, a insólita aparição de algumas palavras, que reiteram, ao mesmo tempo em que transtornam, aquilo que vemos: "heavy swell of the roaring forties", "strong wind", "long take", "close up on swell", "cut to angry sea". A artista escreve sobre o desenho como se fizesse as marcações de uma cena, anotando os cortes e direcionamentos de câmera em um storyboard improvável. A palavra abre o vazio da imagem a outras paragens. Nesses desenhos, as referências ao cinema, à fotografia e à própria história da pintura, emergem de alguma forma, seja através das marcações de plano, ou mesmo pela maneira de apresentação do trabalho, que sugere os desdobramentos temporais do fotograma. $\mathrm{O}$ fato de serem imagens desenhadas sobre um fundo negro, inverte os procedimentos tradicionais da pintura, além de revelar uma maior proximidade com a latência própria da fotografia. Como se fossem imagens em negativo, ou fotogramas de algum filme antigo, o desenho se faz luz na escuridão do subjétil.

Esse trabalho se abre num grande espaço de jogo, em que as imagens pela sua própria migração e perversão, se apresentam iluminadas pela luz emanada delas mesmas, por todos os lados e por todos os meios. Luz intensa que ofusca as fronteiras entre cinema, fotografia, pintura e desenho, para afirmar a imagem em sua capacidade de alternância, de sobreposições, de entrecruzamentos, e também de apagamentos vários. O prazer com a imagem emana nesse trabalho, tão singelo e tão complexo ao mesmo tempo, realizado com a leveza do traço feito a giz sobre um quadro negro. Entretanto, esses materiais mais elementares bastam para fazer surgir o mistério inapreensível das imagens, que nos seduzem pelo que nos fazem pensar, mas também pela capacidade de se enganarem umas às outras, de serem tudo e nada ao mesmo tempo, uma mentira brilhante (BLANCHOT, 2005, p. 255).

Essa insolente extravagância sempre pertenceu às imagens, que jamais permaneceram cativas, idênticas a si, estanques, mas flutuando sempre no fluxo de um movimento sobrevivente que as faz evadir através de novas técnicas de transposição. Cada um desses deslocamentos carrega consigo resquícios de outro tempo, de outro meio e faz com que uma imagem, a cada nova aparição, seja o atravessamento de tudo, uma constelação temporal no instante mesmo em que aparece. É nesse sentido que, diante do trabalho em questão, vemos a irradiação da imagem através do quadro negro, pois não se trata de um desenho construído a partir de uma fotografia, tampouco de uma fotografia dissimulada no quadro, mas da imagem, apreendida no intervalo entre a fotografia e o desenho.

Nesse cenário de sonho, a imagem nasce imersa numa complexa trama de tempo, como o mar, anterior a nós. Na praia, a treva é densa e o mar que não vemos ulula sua voz sem consolo enquanto alguns homens tentam arrastar a embarcação para a segurança da terra firme. Eles se esforçam segurando a grossa corda de marinheiro, feita com um traço largo de giz. Como uma fotografia borrada, que 
registra os movimentos de um corpo numa impressão fantasmática, esse desenho guarda as marcas de um deslocamento, do tempo que passa. Apagamentos vários e sobreposições de linhas e manchas insinuam múltiplas temporalidades na superfície gráfica, denunciando uma duração para além de qualquer instante. A ação de arrastar um barco de volta para a praia, se torna pretexto para falar do tempo que atravessa a imagem e se deixa impregnar no suporte, revelando os rastros de um gesto extinto, mas presentificado pela potência da imagem. No desenho, o então do passado e o aqui do presente se sobrepõem como dois agoras, numa simultaneidade de instantes anacrônicos: o tempo da imagem, mas que segundo Blanchot, "não está fora do tempo, mas que se experimenta como um exterior, sob a forma de um espaço, esse espaço imaginário onde a arte encontra e dispõe seus recursos" (BLANCHOT, 2005, p. 17). Assim, esse outro mar revela o acontecimento que ocorreu, mas que pela imagem, continua a ocorrer incessantemente em sua superfície. Acontecimento que transita entre os apagamentos e as afirmações de cada linha, de cada gesto, em cada figura que empreende uma força descomunal para resistir aos vendavais da imagem e, sempre na iminência do desaparecimento, rasgam a trama do tempo.

Nesses deslocamentos, cinema, fotografia, e pintura se desfazem para deixar emergir a imagem, através de um desenho que não existe mais sozinho, mas povoado e atravessado por mil exteriores, presentes e futuros. Liquidez do traço e dos meios para falar de um mundo também líquido. Esses quadros não representam o mar; eles são o próprio mar, as ondas revoltas, as rajadas de vento, o balanço da embarcação, a vastidão da noite. Não são imagens fixas, mas transitórias, inclusive em sua existência material. Fluem e deixam fluir. Cada quadro, por ser fruto de um instantâneo fotográfico, em vez de suprimir o movimento do primeiro acontecimento, intensifica e amplia o movimento da imagem através de seus suportes sucessivos e do diálogo que estabelece com outros meios e procedimentos, como no caso o cinema, a história da pintura e também a escrita, que existe de forma intrincada nesses desenhos. Eis que surge a imagem como um lugar de passagem, povoada e nômade, aberta a tantos acontecimentos que a perseguem. É esse o espaço de jogo no qual se integram múltiplas técnicas para serem ampliadas, multiplicadas, desestabilizadas e constantemente colocadas em risco, pois a imagem não fixa nada, mas abre tudo ao exterior movediço.

Para além do diálogo que esses desenhos estabelecem com outros meios de pensamento: cinema, fotografia, pintura - procedimento esse que torna mais complexo o entendimento temporal do trabalho -, a própria imagem, por mais antiga que seja, sempre reconfigura o presente no qual se apresenta. Diante dela somos confrontados com uma memória que nos antecede e com uma possibilidade de futuro que também nos ultrapassa. Na tremulante presença da imagem, o que se apresenta é o nosso próprio desaparecimento. Esta é a sua abertura dilacerante, diante da qual, inevitavelmente estamos também diante do tempo.

Quando o tempo se metamorfoseia no espaço imaginário, as coisas perdem seu primeiro aspecto de coisas, para se colocarem lado a lado, convertidas numa mesma substância, nas vastas superfícies reluzentes da imagem. Para Blanchot, a primeira metamorfose é a do tempo, que arrasta o presente em que ela parece ocorrer "para a profundeza indefinida onde o 'presente' recomeça o 'passado', 
mas onde o passado se abre ao futuro que ele repete, para que aquilo que vem volte sempre, e novamente, de novo" (BLANCHOT, 2005, p. 23). Nesse ritmo intermitente de aparição e desaparecimento da imagem, o outrora e o agora estão intimamente ligados pela continuidade densa e substancial da obra. Movimento profundo e vertiginoso, no qual se entrecruzam os mais variados tempos.

O encontro com a imagem, trama singular de espaço e tempo, (BENJAMIN, 2012, p. 108) é sempre marcado por uma volta, um retorno que, contudo, nunca é idêntico. Nesse ir e vir sem fim é a própria obra que se movimenta em direção a ela mesma, em direção ao imaginário, se fazendo enquanto acontece, em uma circularidade que exprime o ritmo de infinitas variações, no qual o alto e o baixo, o passado e o presente se revezam. Entretanto, essa rotação é sem trégua e quando a imagem traz um passado real para o fulgor de seu presente instantâneo, acaba por suspender o próprio presente, retirando-o de si mesmo, e quanto ao passado, desloca-o de sua realidade determinada. Nessa esfera, os pontos são móveis, vão e voltam da superfície à profundidade oculta do centro, cintilando na duração do imaginário. A navegação da obra é, pois, de outra natureza, mas nos arrasta igualmente para o longínquo, para o indeterminado, onde tudo se apresenta e se apaga. Nessa flutuação marcada simultaneamente pela presença e pela ausência, as imagens se arrastam no tempo, se atravessam e se sobrepõem num ritmo lento e infatigável, como as ondas, cujo movimento da superfície é acompanhado por um deslocamento em profundidade, denso e volumoso, que faz emergir as temporalidades anacrônicas.

Tacita Dean sinaliza as intermitências da imagem ao recuperar, em alguns de seus trabalhos, a trágica história do navegador inglês Donald Crowhurst, que tentou dar a volta ao mundo e acabou enredado em sua própria narrativa.1 A trapaça de Crowhurst, não lhe salvou a vida, nem o livrou do encantamento fatal daquela outra navegação, pelo contrário, inscreveu-o no movimento sem volta em direção ao canto de sua própria ficção. Direção essa, que desenraizada, está aquém ou além de qualquer centro e tem no desaparecimento a sua única possibilidade. Ele precisou sucumbir nas águas para que sua narrativa pudesse finalmente emergir anadiômena, tremulante como a crista das ondas. Sua obra consistiu em "fazer do tempo humano um jogo e, do jogo, uma ocupação livre, destituída de todo interesse imediato e de toda utilidade, essencialmente superficial e capaz, por esse movimento de superfície, de absorver entretanto, todo o ser", (BLANCHOT, 2005, p. 7) narrando-se a si mesma. Porque a narrativa - e em sentido ampliado a imagem não é o relato de um acontecimento, mas o próprio acontecimento, já que a ação que ela presentifica é, segundo Blanchot, a da metamorfose. Podemos pensá-la então como o desejo de dar a palavra ao tempo, pois é o tempo cotidiano o que faz avançar o romance. A narrativa em si, se desdobra em outro tempo, naquela outra navegação que é a passagem do canto real ao canto imaginário, como nos diria Blanchot. Nesse encontro reside toda ambiguidade da imagem, que vem, portanto, da ambiguidade do tempo. É ela que possibilita a fascinante experiência de algo que está presente enquanto imagem, embora essa experiência não pertença a nenhum presente, e até mesmo destrua o presente no qual se insere. Assim, se desdobra o tempo na imagem, ao fazer do acontecimento memória e da memória, imagem. 


\section{REFERÊNCIAS}

BENJAMIN, Walter. Magia e técnica, arte e política: ensaios sobre literatura e história da cultura. São Paulo: Brasiliense, 2012.

BLANCHOT, Maurice. O espaço literário. Rio de Janeiro: Rocco, 2011.

BLANCHOT, Maurice. O livro por vir. São Paulo: Martins Fontes, 2005.

DEAN, Tacita. Tacita Dean: A medida das coisas. São Paulo: IMS, 2013.

DIDI-HUBERMAN, Georges. Ante el tiempo: Historia del arte y anacronismo de las imagines. Buenos Aires: Adriana Hidalgo, 2011.

FOUCAULT, Michel. Estética: literatura e pintura, música e cinema. Rio de Janeiro: Forense Universitária, 2009.

ROYOUX, Jean-Christophe. Tacita Dean. Londres/ Nova York: Phaidon, 2006.

Recebido em 05/09/2018 - Aprovado em 05/10/2018

Como citar :

FREITAS, R. O tempo redesenhado: tramas da imagem. ouvirOUver; Uberlândia, v.14,n.2, p.322-328, jul./dez. 2018. Disponível em: http://www.seer.ufu.br/index.php/ouvirouver; DOI:http://doi.org/10.14393/OUV23-v14n2a2018-5

(c) (i) \& A revista ouvirOUver está licenciada com uma Licença

Creative Commons Atribuição-NãoComercial 4.0 Internacional. 